\title{
Fetal Dreams and the Source of Desire
}

\author{
Bradley Y. Bartholomew \\ Independent Researcher, France
}

Copyright $(2017$ by authors, all rights reserved. Authors agree that this article remains permanently open access under the terms of the Creative Commons Attribution License 4.0 International License

\begin{abstract}
This paper presents the theory of French neurophysiologist Michel Jouvet that REM dreaming sleep acts as a genetic programming mechanism for the brain in utero. In addition the French neurobiologist Jean-Didier Vincent in his book Biology of Passions provides a great deal of research material concerning the development of the fetus as a desiring subject. This material is presented in support of the general theory of desire principally developed by French psychoanalysts Françoise Dolto and Jacques Lacan. It is shown that at the time of birth the fetus has already developed a desiring attachment to the conditions in the womb and that the act of being born does represent a rupture to its established desiring patterns thus reinforcing and explaining all the theory that has emerged concerning the trauma of birth.
\end{abstract}

Keywords Otto Rank, Roffwarg, Muzio, Dement, CNS, Placenta, Umbilical Cord, Amniotic Fluid, Womb

\section{Introduction}

It has been known for decades that the fetus in utero spends most of its time in a state akin to REM (Rapid-Eye-Movement) dreaming sleep. There also seems to be little doubt that this state of sleep is a key factor in the development of the central nervous system.[1] This article will examine the complementary theory of Michel Jouvet that the fetal dreams are actually responsible for programming the developing brain in utero. If we combine Jouvet's theory about fetal dreams with the theory of neurobiologist and philosopher Jean-Didier Vincent concerning the Biology of Passions we come up with a clear concept of what is being programmed into the developing brain. We shall also look at the writings of a variety of theorists and psychoanalysts including those of Françoise Dolto and Jacques Lacan concerning the source and nature of desire with a view to arriving at some sort of understanding of our psychological heritage.

\section{Dreams as Genetic Programming}

Michel Jouvet advanced the theory that certain genetic programs are periodically reinforced in the brain and this reinforcement first establishes and then maintains the functionality of the synaptic circuits responsible for our psychological heritage. He felt that such a system had the advantage of reestablishing certain circuits that may have been altered by epigenetic factors, which are factors not strictly determined by our genes. This genetic reprogramming occurs during the phase of sleep he called 'paradoxical sleep' also known as REM (Rapid Eye-Movement) sleep, which is generally considered to be the time when we dream. [2]

Jouvet advanced three keys for unlocking the enigma of paradoxical sleep. Firstly that dreaming mechanisms require a lot of energy through the consumption of oxygen. Secondly the likely reason why the so-called 'cold-blooded' animals, namely fishes, amphibians and reptiles do not appear to engage in paradoxical sleep is that their nerve cells continue to divide throughout the life of the animal. This is contrary to the situation with homothermal animals that maintain a constant body temperature independent of their external environment. The third key in relation to the latter species, namely mammals and birds, is that the more immature they are (in utero or in vivo) the more something resembling paradoxical sleep (referred to as 'active sleep') becomes important.

According to Jouvet, there are many studies that show a positive correlation between the immaturity of the nervous system and the fragility of the thermoregulation system of the neonate mammal, and the increased proportion of time spent in paradoxical sleep. A human neonate will spend 50 to 60 percent of its sleep-time in paradoxical sleep. A kitten or baby rat can spend up to 80 or 90 percent of its sleep-time in paradoxical sleep. This significant increase in paradoxical sleep has also been found to apply in utero for the fetuses of many mammal species. Jouvet points out that it is precisely at the time the nervous system is finishing its initial maturation and genetic programming that the amount of paradoxical sleep, which in due course will become dreaming sleep, attains its greatest proportions. After this initial maturation process the amount of paradoxical sleep gradually decreases. This has to be a very significant phenomenon.

Jouvet's primary research as a neurophysiologist was to 
locate the mechanisms in the brain responsible for paradoxical sleep. According to him the topography of neurons (more than likely cholinergic) that constitutes the endogenous generator of the activity ponto-geniculo-occipital (PGO) of dreaming has been defined precisely. It is situated in the reticular formation of the pons in the brain stem. The routes are also known whereby the PGO activity reaches the centers for motor ocularity, which causes the rapid-eye movements of dreaming sleep. The ascending paths leading to the cerebral cortex, either directly or via an intermediate thalamic relay have been equally defined with great precision.

By blocking the inhibitory system which prevents motor discharges during paradoxical sleep, Jouvet found that a sleeping cat will perform certain characteristic behavioral patterns as if it is acting out its dreams. The animal will get up quickly and start walking as if it is stalking an imaginary prey. It will then stop and demonstrate the characteristic gesture of catching a fish. Other stock actions can quickly follow. It may demonstrate fear with its ears back, or open its jaws wide in the snarling hiss of feline rage, or even feign an attack with quick backward movements of its paws and biting movements in thin air. It will also groom itself by licking its paws and flanks but it can equally start licking the perimeters or floor of its cage. Jouvet stresses that these behaviors occur without any external visual or auditory stimulus, and thus indicate that the dream is a programmed activity of the brain. In this context, he recalls a remark made by Piaget that a dream resembles a game inside the brain.

Jouvet fundamentally poses the perennial question of nature versus nurture. If dreams are a genetic programming mechanism for the brain, then they would be responsible for the individual variations in the instinctive activities and behaviors of animals as well as being responsible for human personality traits to the extent that they are innate or inherited. That is to say, that part of our psychological heritage which cannot be attributed to our environment, our culture or learning. If Jouvet is correct, the importance of dreams during our formative years cannot be overemphasized and our dreams continue to iteratively program the subtlest reactions of our waking consciousness throughout life.

Fetal movements are without doubt the expression of motor discharges caused by the genetically programmed formation of synapses during the maturation of the central nervous system, according to Jouvet. It is impossible to deny the influence of the environment in utero in the behavior and comportment of the neonate, and it is equally certain that the genetic program plays a predominant role in the stereotypical movements of approach to the mammary, of twitching and sucking which occur during periods of paradoxical sleep in the neonate.

For Jouvet, it is difficult to understand how a definitive genetic program established at the end of the initial maturation period can efficiently organize future innate behaviors given the plasticity in modifications of the synaptic connections induced by environmental causes.
Furthermore, the definitive genetic program of hundreds of billions of synaptic connections would require a great many more genes than are known to exist in the genome. For these reasons, the concept of a recurrent or periodic genetic programming appears more satisfactory. This endogenous periodic process would excite at regular intervals the synaptic structures responsible for the recognition and processing of stimuli which produce stereotypical innate behavior. An obvious candidate for such a periodic genetic programming is paradoxical sleep.

However, Jouvet also raises various questions about his theory. There is no proof of the existence of paradoxical sleep in the vertebrates (fishes, amphibians, or reptiles) although fishes and amphibians do display the alternative states of activity and repose, and variations of electrical activity can be detected in the brains of sleeping reptiles. The question therefore arises as to how the brains of these other species are programmed if not through paradoxical sleep.

Another major doubt is the proposition that the sleep of the mammal in utero is not true paradoxical sleep but merely the forerunner of paradoxical sleep. This sleep of the fetus has been termed active, and is characterized by movements that reflect the intrinsic property of each motor element to activate strongly without central coordination. The ontogenesis pre- and post-natal is accompanied by a transition, the limits of which are uncertain, between the end of the genetic programming by neurogenesis of the central nervous system and the appearance, at first slowly and then more rapidly, of a new mode of programming affected by paradoxical sleep.

Jouvet also raises the issue that the suppression of paradoxical sleep through the use of certain drugs does not seem to produce any symptoms that can be attributed specifically to the absence of paradoxical sleep. He cites the case of patients being treated for narcolepsy or depression who take drugs for several months (inhibitors of monoamines oxydases and tricyclical antidepressants), which suppress totally or almost totally their paradoxical sleep. Also the literature concerning the retention of learning and paradoxical sleep seems to contain a similar number of positive and negative results, according to Jouvet. These results certainly do not prove that paradoxical sleep is responsible for an iterative genetic programming process. However, they do suggest that it is illusory to test the effects of paradoxical sleep deprivation on a genetically heterogeneous population because each member can react in a different fashion.

The final, and potentially major, concern is caused by the fact that some people dream a great deal and others claim to dream very little, if indeed at all. Jouvet quotes in English a statement by Mayr: "Genetic variability is universal, a fact which is significant not only for the student of morphology but also for the student of behavior. It is not only wrong to speak of the monkey but even of the rhesus monkey... The time has come to stress the existence of genetic differences in behavior... Striking individual differences have been 
described for predator-prey relations, for the reactions of birds to mimicking or to warning colorations, for child care among primates, and for maternal behavior in rats. It is generally agreed by observers that much of this individual difference is not affected by experience but remains essentially constant throughout the entire lifetime of the individual. Such variability is of the greatest interest to the student of evolution, and it is to be hoped that it will receive more attention from the experimental psychologist than it has in the past..." [3]

Jouvet's book was written prior to the controversy about paradoxical sleep introduced by Solms in 1997. By studying patients with neurosurgical lesions, Solms was able to differentiate REM sleep, as defined by purely physiological criteria, from dreaming, a psychological process. These two processes occur simultaneously, but that does not mean that they are one and the same thing. Solms makes two assertions. He found that patients with lesions in the brain stem continued to dream. This fact is very surprising because as outlined above, the work of Jouvet is based on PGO activity being responsible for initiating paradoxical sleep. By the same token, other patients that had lesions in the parietal and frontal lobes of the brain did not dream at all. Solms concluded that the anterior structures of the brain are essential for dreaming, but not the structures in the brain stem. [4]

Following the work of Solms it becomes even more reasonable to assert that the fetus is actually dreaming in utero. The fact is that by the third trimester of gestation the anterior regions of the brain of the human fetus are largely developed. Taking the work of Jouvet, Roffwarg et al. and Solms together, it is highly likely that the active sleep of the fetus is a key factor in the development of the central nervous system (including the anterior regions of the brain), which means that it is a genetic programming mechanism for our innate behavior and psychological heritage.

The dreaming aspect of REM sleep becomes an extension or continuation of the original active sleep. Fetal dreams commence at a time when the central nervous system is substantially developed and is in the nature of a window into our genetic programming. Dreaming is not of itself a programming mechanism, but as a result of our dreams, we can get a glimpse of what our genetic programming is all about. To dream or not to dream becomes a non-essential phenotype of the genetic code which some of us experience but others do not, and recalls the statement made by Mayr above concerning the individual differences in our psychological heritage. In this way we can still assert, consistent with the theory of Jouvet, that our innate passions are being genetically programmed in utero during the active sleep.

\section{Biological Basis for Desire}

Jean-Didier Vincent advances a concept of a fluctuating central state on which he founds a biological explanation for passion. [5] In a later work, he speaks of opposing processes. [6] The evolution of the species consists of a progressive increase in the number of intermediaries between information coming from the external world and factors responsible for our actions. The degree of liberty or free will of the animals increases with the number of these intermediaries. But it is because of the liquid element, and the substances transported therein, which introduces a solution of continuity in the organization of cells that this liberty or free will is possible. His approach to explaining the passions is therefore preceded by a study of the body's humors, that is to say the liquid elements of the organism and the substances which, in opposing and fluctuating processes, permit the communication.

Dispersed throughout the body, either scattered or grouped within glands, specialized cells introduce into the blood stream secretory products or hormones. These cells are called endocrine to distinguish them from the exocrine glands which secrete their sugars and liquids externally or in the digestive system (sweat glands, salivary glands etc.) The endocrine glands are a familiar element in the anatomical landscape. Some of the better known ones are the thyroid gland, the gonads or sex glands, the hypophysis, and the pancreas. The same gland generally contains many types of cells. The anterior hypophysis, for example, contains at least five types of cells which each secrete one or more hormones. The endocrine pancreas, as distinct from the exocrine pancreas which has a digestive function, secretes three hormones; insulin which reduces the amount of sugar in the blood, glucagon which increases the amount of sugar, and somatostatin which inhibits the two preceding secretions. The same hormone can be secreted from different sources. Many hormones secreted by the digestive tract are also released in the brain. The walls of the digestive system is an extended gland with a large repertoire of endocrine secretions; the gastro-intestinal hormones. Other organs and tissues, while not directly endocrine glands, also are capable of secreting hormones (liver, kidneys, blood cells etc.). The nervous system itself also acts as a multifunctional gland liberating neurohormones and neurotransmitters with hormonal actions.

In general terms Vincent explains that the hormones have a double function. On the one hand, by assuring communication between the cells, they integrate the chemical and physiological functions to maintain a constant state, and adapt the responses of the organism to changes in the environment. On the other hand, they are indispensable for the complete and harmonious development of the neonate, the growth of the individual, and the proper functioning of the bodily organs in adulthood. For the most part the hormones are directly synthesized from the genetic code and their presence and interaction within the brain and body of the organism is in the nature of programming determined by the genetic code.

Again in general terms, Vincent states that desire is 
located somewhere between joy and need, profit and loss. The satisfaction of a need that leads to reinforcement is the basis of learning theories. Desire also holds a central place in Freudian psychology based on need and the experience of satisfaction. But more than need, it is perhaps the sense of lack, the anticipation or simulation of need, which is at work in a sustained feeling of desire.

One of the primary characteristics of a desiring behavior pattern is found in the association between an affective or emotional component and the anticipation of the outcome of the action. Vincent tells us that this involves visceral manifestations and hormonal secretions that offer a veritable somatic translation of the emotion. The emotional landscape that accompanies a desiring behavior pattern is the hallmark of desire, and demonstrates the difference from a simple instinct, that is an affective desert by comparison. It is suggested that fetal dreams are responsible for the affective or emotional component of desire that occurs simultaneously with the programming of the hormonal milieu in utero. The affective or emotional component is our psychological heritage.

The catalogue of substances that contribute to the central fluctuating state is extensive. For example noradrenergic pathway acting in the brain of a female rat will cause her to accept the advances of a male rat. By the same token, luliberin, in conjunction with the male hormones, will transform a timid hamster afraid of an aggressive female into an intrepid and willing lover. Acetylcholine modulates the activity of the prefrontal cortex and the limbic system. The morphine peptides, the receptors for which abound in the cerebral cortex, regulate the level of sensory input. Finally there are the neuropeptides, the list of which never ceases to grow, that are the ingredients of our central nervous system and whose workings are often mysterious.

The multiplicity of chemical substances is not the only complicating factor. The dispersion of nerve terminals, their interdependency, and the magnitude of their numbers contributes to the confusion. The same nerve terminal can liberate many substances; dopamine for example as well as cholecystokine. In addition this amine is not only liberated at the terminal level but equally within proximity of the cell bodies at the dendrite level. Dopamine is also capable of controlling its own release.

Vincent speaks of a non-specific activation for which dopamine is responsible. This non-specific activation is a general phenomenon that applies to all behavioral patterns or comportments independent of sensory input. This is desire devoid of all specificity and, as such, is considered as the foundation of spontaneity. However, for this desire to have full and optimal effect it has to attain a level above which its operation is harmful. Lesions of the hypothalamus that interrupt the operation of the dopaminergic fibers of the reticular formation which communicate with the anterior regions of the brain, will cause an animal not only to cease to eat and drink, but also to display a state described as akinesy or catalepsy. The animal loses all spontaneity (shows zero desire), ceases to move and retains the posture in which it is put by the experimenter.

The lateral hypothalamus is also considered to be a pleasure center in the brain. Vincent refers to Panksepp's definition of the lateral hypothalamus as a 'goad without goal', a non-specific prod. As an adjunct to desire, the prod activates the appropriate behavior. The choice of behavior is determined by the principal object present in the environment. Given that the conditions of the interior milieu are right (hormones, composition of the blood etc.) the vision or scent of a consenting female will cause the animal to copulate, or the presence of food will stimulate the animal to eat. When the lateral hypothalamus is stimulated electrically, the behavioral response will be determined by the nature of the stimulus present. In this regard it is considered that the lateral hypothalamus maintains a non-specific behavioral tension.

The lateral hypothalamus is also a site for auto-stimulation. A rat that is wired in such a way that it can electrically stimulate this part of its own brain by pressing on a lever will soon become addicted to the sensation. It becomes incapable of denying itself this pleasure. A starving animal that has the choice of two levers, one which will furnish food and the other which will allow it to auto-stimulate, will choose the latter even at the cost of its own life. The animal is insatiable and shows no signs of becoming accustomed to the pleasure. Depriving it of the lever is the only way to stop it. The lateral hypothalamus is not the only pleasure center in the brain. There are others in the limbic and striatal structures of the anterior brain and in the brain stem.

Auto-stimulation and the pleasure derived from it will have no physiological significance if it cannot be combined with a natural action. Consequently it has been found that electrical stimulation of all these sites of auto-stimulation induces, depending upon the place and conditions, all the behaviors of which a rat is capable; sniffing, eating, drinking, grooming, transporting and collecting objects, digging, copulating, killing mice, gathering its young. Vincent says that it is hard to escape the idea that neuronal circuits developed according to plans laid out in the genetic code, revised and corrected by learning, are responsible for these different behaviors.

Vincent tells us in his later work [6] that the same hormone that seems to be at work in religious and mystical ecstasy also plays a large part in sexual orgasm. In both cases there is a massive liberation in the hypothalamus of the hormone oxytocin. This same hormone can also act as a neurotransmitter in the neuronal networks implicated in the regulation of functions of attachment and to social memory. Oxytocin is effectively a neurohormone synthesized by the hypothalamus and liberated by the anterior hypothysis at the time of breast-feeding; its secretion being in the form of pulsating discharges as a reflexive response to the suckling of the baby causes a periodic ejection of milk. This substance is also liberated inside the brain at the level of nerve terminals in the hypothalamic and limbic (preoptic and 
septum) system. A massive secretion occurs at the moment of orgasm for both sexes.

In explaining love from a biological point of view Vincent says that there exists a need for an 'other' just as there is a biological need for water or for proteins, and this need for another is what constitutes the desire called love. For the biologist, the state of being in love is only a particular form of the central fluctuating state, as it expresses the presence of the other in external space. The sexual partner epitomizes the other. The state of being in love is accompanied by a transformation of the body for both parties. The role of the sexual glands is a determining factor. The sexual hormones act directly on neuronal receptors in the brain. Hormones such as prolactin and luliberin are concerned with the genesis of being in love. However, the secretion of the sex glands alone does not bring about this state of being in love. Desire is universal and is tied up with the proper functioning inside the brain of the desiring systems of which sexuality is just one aspect. Love represents a fusional state in which the individual can realize its own unity with the other. And in the case of humans, language becomes the essence of love in which the sexual organs play a minimal role. In other words, over and above the secretion of hormones and the fluctuating state of the central nervous system as a matter of pure biology, love is also intimately dependent on our psychological heritage.

In addition Vincent cites with approval a passage by Freud that there are many other types of love apart from the common conception of sexual love constituted by a sexual union. We can't separate the love of self, parental and familial love, friendship and the love for humankind in general any more than we can separate attachment to material objects and to abstract ideas and causes because all these varieties of love are expressions of one and the same tendency; a tendency that in certain cases invites a sexual union but in many other cases is directed towards other ends. The word love brings about a synthesis in language of a multiplicity of significations. They all express in one way or another the operation of desire which brings us back to a biological need for the other, and a sense of lack as part of our psychological heritage.

Vincent maintains that our subjectivity, that is to say, our psychological heritage is derived from the body of the mother. An infant knows its mother even before meeting her. A new born rat, crawling and blind, finds its way with the certainty of someone who knows to the maternal mammary. To detach it from its mother is a sensation comparable to picking a fruit from a tree. If its sense of smell is destroyed, or if the maternal mammary is washed with detergent, it is no longer able to find the mammary. However if the maternal mammary that has been washed with detergent is then covered with amniotic fluid collected at the time of birth, the newborn rat is again able to find its way to suckle. The mother rat instinctively licks the amniotic fluid from its newborn and licks its own mammary, so that her young are attracted to the mammary by the odor.
If the natural odor of the amniotic fluid is changed by injecting a lemon flavor into the uterine environment some time prior to birth, the baby rat will elect to attach itself to a lemon flavored mammary if forced to choose between several mothers. The story does not end there. The male adult demonstrates the same affinities towards a female with a lemon flavored vagina. The male adult will take twice as long to ejaculate with a female rat that does not exude a scent of lemon. Vincent argues for a perfume of infancy which will play a key role in the sexual attachments of the adult, whether male or female. It seems clear, at least, that the heterosexual male will seek to find in the female the olfactory image of its mother, an image derived originally from the amniotic fluid. Vincent refers to the conclusion drawn by Chateau that there exists in the brain of the mother and the infant a biogrammar that fixes, of which the rules of syntax determine language, the behavior of attachment between mother and infant. These are the constituents of our psychological heritage; programmed emotions, gestures and language that form the base of what sociolinguists call intersubjectivity.

In his later work, Vincent reminds us that the study of grammar amounts to the analysis of true functions (expansion, coordination, subordination etc.) to the point where it is no more absurd to talk of the physiology of language than it is to talk of its genetic origin.[6] A statement by Paul Guillaume is quoted with approval that it is a banal fact that the advent of vocal reactions is under the influence of the general infantile state of emotions and needs. In the initial period of life the cry corresponds to suffering, to physical discomfort and to hunger; later to more complex feelings of displeasure. One can distinguish at the end of the second postnatal month cries characteristic of desire, impatience and deception. Later other vocal reactions develop with the state of well-being and agreeable excitement. The direct action of the affective state on the vocal organ does not find its expression simply through the cry of an infant; potentially here lies the natural root of developed language. It is impossible to separate the acquisition of language with its related affects and emotions. Language merges into our psychological heritage and, according to Jouvet's theory, is programmed into the brain of the fetus during paradoxical sleep.

\section{Life before Birth}

An article in New Scientist (9 May 2015) entitled "Yum, yum, a gulp of nutritious womb milk", highlights the obvious fact that desire develops almost immediately after fertilization.[7] Researchers have found that during the first 11 weeks after fertilization, before the mother's nutrient-rich blood supply is plumbed in, the lining of the uterus directly secretes large amounts of glucose as glycogen directly into the womb. The glycogen is abundant in the recesses of the womb lining, where it is broken down into smaller molecules 
that are absorbed into the placenta. We will see later in this article just how important emotionally the loss of the placenta is to the new born but it will also be of interest just how much the oral cavity (mouth), tongue, taste buds and jaw have developed during this first trimester of gestation, meaning that there cannot be the slightest doubt that the embryo is actually drinking and enjoying this "womb milk", and in fact this must be the first and primary enjoyable experience at the beginning of life.

Between 5 and 6 weeks, a light touch to the mouth area causes the embryo to reflexively withdraw its head. The embryo has brainwaves by 6 weeks, 2 days. By 7 weeks, cell groupings resembling taste buds appear on the tongue and hiccups begin. The jaw bone begins to develop. Also by 7 to $71 / 2$ weeks, nephrons, the basic filtration units in the kidneys, begin to form which means that fluid is passing through its body. By eight weeks, touching the embryo can produce jaw movements as well as other movements. The embryo now possesses more than 90 percent of the structures found in the adult. By 9 weeks thumb sucking begins and the fetus may swallow amniotic fluid. The fetus can also grasp an object, move the head forward and back, open and close the jaw, move the tongue, sigh, and stretch.

It is never too early to speak of a human being, declared Françoise Dolto at the end of the 1970s. It is an être de parole (a being capable of communication) even as a fetus and it is easy to understand why a mother and father speak to the fetal person who is in the uterus of the mother. Dolto explains what she means by an etre de parole: a being who has a need to be spoken to, to be addressed directly, a being for whom language is essential, vital, because it has a thirst for communication and knowledge. This is the human being from the beginning to the end of its existence. For the infant the need for communication is as necessary as nourishment for the metabolism of the body. Dolto was convinced of the existence of a symbolic function peculiar to humankind. As vital as our vital functions, this factor is at work during the life of the fetus in utero at the very heart of the exchanges between the mother and her progeny. The fetus is not just living, it is desiring, perceiving, communicating and memorizing. At the heart of the fetal night it has joys and torments, it knows happiness and unhappiness. It is a communicator in the making. [8]

Dolto formulated the concept of an unconscious archaic memory of life in utero. A memory of an affective relation with its umbilical cord, of its liquid environment immersed in amniotic fluid, with the placental envelopes. In other words a memory of its universe at the time; the matrix, that is to say the maternal womb. The fetus in effect bathes in the amniotic fluid. That archaic image of being self-linked to its mother in utero, symbolizes in the infant unconscious its basal security. This unconscious archaic memory of life in utero is, according to Dolto, also the beginnings of the unconscious image of the body for the being to be born. These are the concepts that make up our psychological heritage, that Jouvet would have us accept is programmed into the brain by the paradoxical sleep of the fetus. By the same token Dolto speaks of sleep in the adult as a state of natural regression to the fetal stage.

For Dolto every human being is a desiring subject. Human beings aspire to communicate from conception onwards. The unconscious image of the body is the concept which permits Dolto to take into account continuity of being, before and after birth, which is the subject. What separates the body of the infant from the body of the mother, and makes it viable, is the umbilical cord and its ligature. The umbilical originates the body schema within the confines of an envelope that will become the skin (the placenta and the envelopes contained in the uterus having been cut away). The image of the body, made up partially of the rhythms, the warmth, the sonorities, the fetal perceptions, finds itself abruptly modified with the change in perceptions at birth, in particular the loss of the passive auditory pulses of the double heartbeat that the fetus heard in utero. This modification is accompanied by the advent of breathing through the lungs, and the activation of the peristaltism of the digestive tube which, when the infant is born, emits the meconium accumulated during the fetal period. The umbilical scar and the loss of the placenta, a fact in the course of human destiny, can be considered as the prototype of all the experiences that will be called castrations (including genital). This first separation should be called umbilical castration. It is contemporaneous with birth, and it is the foundation, in the modalities of joy and anguish which accompanied the birth, of the infant's subjective relations of desire for others. [9]

\section{The First Attachment}

The expulsion of the placenta is hardly talked about in most prenatal groups that prepare the mother for the birth, but the infant is born with the placenta. Almost a half an hour can pass before the expulsion of that thick spongy mass, beautiful for some, formidable for others, with a very particular odor. The expulsion of the placenta often surprises the mother because of the pain and the contractions that it reinvokes. Mothers often consider that it's all over when the baby is delivered. Doctors and midwives on the other hand monitor with vigilance the expulsion of the placenta, for if retained in the uterus, even with modern medicine, it can be a source of important complications, at times even dramatic. The echoes from the birthing room can be a matter of life and death.

But what is actually delivered? Is it simply an anatomical mass, an organ which no longer has a function, and is only of interest to research laboratories and to the cosmetics industry? Or is it a profoundly intimate companion which is no longer of use to us, from which we are forced to separate by nature, and which, after the first loss, that of the amniotic fluid, prefigures the first lost object, and evokes the paradise lost common to so many, if not all, originating myths.[10]

The placenta, the perfect union between two beings, rises 
to a state that no other organ can equal. It cannot be considered as a parasite and is in the nature of a transplant, expressed by both organisms and rejected by neither. It is the symbiosis and parabiosis of two beings united in the flesh, and yet the blood remains separate. The placenta is the seat of all the transfers of nutriment or waste product, oxygen, carbon dioxide, sugars, lipids, proteins and vitamins. The placenta plays an active role; it is the indispensable relay between the two organisms. At its peak in the thirty-fifth week of gestation, the maternal blood flow to replenish the villosities will attain thirty-six litres an hour. [11]

Certain analysts maintain that at the outset, the infant sees itself and thinks of itself as being one with the mother. That it is not the mother who incorporates the infant into herself, but it is the infant that achieves unity with the mother, and lives as if it is a part of the maternal body, just like a leaf on the branch of a tree. When one studies what occurs between the maternal circulation and the fetal circulation, it is clear that the placenta creates a barrier, a frontier, strictly delimiting two territories; certain substances pass through the placental barrier, and others are stopped. The placenta is an obstacle to the unification fantasy, the desire to be at one with the loved one, a fantasy fundamental to humankind. In playing this role as obstacle it is also an organ protecting the fetus from the mother. [12]

After the birth the mother does not disappear. She is there, attentive, taking care of the infant. It is precisely the placenta that has disappeared. The cut is located at this level, between the infant and that part of itself. So why do we so often describe the birth as a separation between mother-infant? Why don't we talk of an umbilical cord that has to be sliced between the mother and the infant? Instead it is necessary to cut the umbilical cord. Everything happens as if the umbilical cord unites the mother and the infant, as if they communicated with each other, as if the umbilical cord was in the nature of a mirror where each is a reflection of the other, that each is the double of the other and yet, at the same time, contained within the other. [12] The placenta is actually an amputated limb of the neonate and as such remains in our psychological heritage as a phantom.

The fetus is inside; but this 'inside' is already an 'outside' because its sensory organs are continually informing it about what is happening from afar. We know that it is listening attentively when it is awake, perceiving from a distance, obtaining information about everything that is happening in its neighborhood, in what we could call its territory. Listening to our words, participating in its own way, and living in a world structured by language. The mother eats curry and the amniotic fluid has a curry taste. The fetus is permanently savoring this liquid; it drinks two and a half litres per day, and we know that its tongue, its mouth and the upper part of the esophagus are constellated with gustatory papillae that will disappear at the time of birth. Because of the placental function, the infant, so tiny and weak, has an astonishing power of attraction, and of suction of liquid elements and of their dissolved content. It is this power of suction that causes the milk to rise in the maternal breast. The placenta is the window for the fetus to the world outside preparing the fetus for its future life. Because of its operation the fetus is neither inside nor outside. [12]

Now we can appreciate the anguish of birth, the emergence from the primordial aquatic milieu when it exits from the amniotic fluid; the leap into a world where its lungs come into play, where it has to breathe air in order to survive. The trauma of birth is not separation from the mother per se but the strangeness of this new milieu so strikingly different. Lacan attributes to this moment the anguish of birth, inherent in life, inevitable, an anguish which can project its shadow for the rest of life. The infant has lost in this adventure of birth that part of itself from which it becomes separated, discarded, abandoned, the 'book of flesh' that was the placenta engaged in signifying relations with the mother and the external world. The important thing is to know that this abandoned object is at the base of all that is desirable in life, because now it has disappeared. It instills in reality a sense of lack, of emptiness [12].

If the subject that is born situates itself and constitutes itself in a rapport with the Other, because it is born to the extent that it is represented by the signifier (the signifier brings the subject into existence because it only has meaning as a signifier for other signifiers), we have to recognize with Lacan that, in this operation, something remains which becomes 'object-cause of desire', the lost object where the function of cause can take root. [12]

Therefore at the base of subjectivity, in front of all other objects, at the horizon of being, there is this object irretrievably lost, and the desire functions inside a bubble which, although burst, still contains the trace of what it originally enclosed inside the envelope. We desire because we have been deprived of the liquid world, of our envelopes, of our placenta. This means that the experience of that severance marks the subject in all its development, the relation of subject to object being always felt as unsatisfying. It cannot bring contentment, it cannot bring security. The object will always be the cause of desire, according to Lacan, the cause of an unsatisfied desire. "Where the Thing was, one could say, I have to be" because we are desiring subjects. A fact of nature divides us... in order that we may be born. [12]

\section{Conclusions}

It is well established that the fetus in the womb spends the bulk of its time in REM sleep and there can be little doubt that this plays a vital role in the development of the central nervous system, not just the physical growth of the central nervous system by directing the neural connections etc. but also the programming of the central nervous system consistent with the creation of a functioning living being. Given the fact that the fetus spends so much of its time in this clearly identifiable state of REM sleep, which actually involves stimulation of the genitalia as well, it is reasonable 
to assume that the developing being is being programmed with a capacity to desire. It is also reasonable to assume that the primary source for this state of REM sleep comes from the genetic code which contains all the instructions for the desiring living being to be created. It is impossible for us to tell what information and imagery could come directly from the DNA to form the content of fetal dreams but what is clear is that the fetus actually has a wide variety of sensory experience in the womb; tactile, auditory, olfactory and taste. It is swallowing amniotic fluid and we have seen that from the very beginning the amniotic fluid contains glucose which means there is some stimulation of the taste buds. Facial expressions such as smiles and sneers are common for the fetus as well. The fetus is a living being and it is reasonable to assume that it is dreaming about its experience in the womb, that is to say its experience about the conditions in the womb and its attachment to the mother.

\section{REFERENCES}

[1] Roffwarg H., Muzio, J., \& Dement, W. (1966) Ontogenetic development of Sleep-Dream cycles, Science, 52,604 - 619.

[2] Jouvet, M. (1992) Le sommeil et le rêve [The sleep and the dream]. Paris: Odile Jacob.

[3] Mayr, E. (1958) Behavior and systematics. In Roe, E., \& Simpson, G. (Eds.) Behavior and evolution. New Haven: Yale University Press.
[4] Bléandonu, G. (2002) À quoi rêvent nos enfants? [What do our infants dream about?]. Paris: Odile Jacob.

[5] Vincent, J-D. (1986) Biologie des passions [Biology of passions]. Paris: Odile Jacob.

[6] Vincent, J-D. (1996) La chair et le diable [The flesh and the devil]. Paris: Odile Jacob.

[7] New Scientist, Yum, yum. A gulp of nutritious womb milk, May $9,2015$.

[8] Canault, N. (2001) Comment le désir de naître vient au foetus [How the desire to be born comes to the fetus]. Paris: Desclée de Brouwer.

[9] Dolto, F. (1984) L'image inconsciente du corps [The unconscious image of the body]. Paris: Le Seuil.

[10] Rapoport, D. (1989) Pourquoi le placenta dévoilé [Why the placenta unveiled?]. In A. Bouchart, D. Rapoport, \& B. This (Eds.), Les cahiers du nouveau-né 8: Délivrances ou le placenta dévoilé [The journal of the neonate 8: Deliveries or the placenta unveiled] (pp. 9 -12). Paris: Stock.

[11] Clément-Faraut, C. (1989) Le délivre [The delivery]. In A. Bouchart, D. Rapoport, \& B. This (Eds.), Les cahiers du nouveau-né 8: Délivrances ou le placenta dévoilé [The journal of the neonate 8: Deliveries or the placenta unveiled] (pp. 43 96). Paris: Stock.

[12] This, B. (1989) Le placenta: médiateur, protecteur, premier objet perdu? [The placenta: mediator, protector, first lost object?]. In A. Bouchart, D. Rapoport, \& B. This (Eds.), Les cahiers du nouveau-né 8: Délivrances ou le placenta dévoilé [The journal of the neonate 8: Deliveries or the placenta unveiled] (pp. 109 - 140). Paris: Stock.

[13] Baas, B. (1992) Le désir pur [The pure desire]. Louvain: Éditions Peeters. 